\title{
Pengaruh Faktor Kesadaran Halal, Harga, Pelayanan dan Religiusitas Terhadap Keputusan Pembelian Orichick di Kota Semarang
}

\author{
Iqbal Esa, Fuad Mas'ud, Edy Yusuf Agung Gunanto \\ Ekonomi Islam,Universitas Diponegoro,Semarang
}

\author{
Iqbalesa90@gmail.com
}

\begin{abstract}
Indonesia is one of the potential countries in terms of the Muslim consumer market, this is evidenced by the high Muslim population that reaches 209.12 million or around $87 \%$ of the total population. The influence of kesadaran halal in society is still considered less than optimal. The culinary business continues to increase, but in fact the halal certification that guarantees the halal haram of a product is still minimal, plus the increasing buying interest of consumers in Semarang City for ready-to-serve products (franchises) which are generally still controlled by foreign parties.This research is a form of quantitative method that is distributed through a questionnaire. The population in this study were Muslim student consumers who had bought and eaten OriChick products in the city of Semarang. The total sample was 100 respondents with a purposive sampling approach. This study uses multiple linear regression analysis techniques where the data is processed using SPSS Statistics 23. The results of the analysis show that the impression of price and ic religiosity has a positive and significant effect on purchasing decisions. Meanwhile, kesadaran halal and service quality variables do not have a significant effect on purchasing decisions. Simultaneously the results of kesadaran halal, price impressions, service quality and ic religiosity have a simultaneous effect on purchasing decisions. The result of the $R$ square value test of 0.346 shows that $34 \%$ of purchasing decisions can be explained by independent variables and the remaining $66 \%$ is explained by other factors outside the research.
\end{abstract} Keywords: Consumer Behavior, Kesadaran halal, Price Impression, Service Quality, ic Religiosity, and Purchase Decisions

\begin{abstract}
ABSTRAK
Indonesia merupakan salah satu negara potensial dalam hal pasar konsumen muslim, hal ini dibuktikan dengan tingginya penduduk muslim yang mencapai 209,12 juta jiwa atau kisaran $87 \%$ dari total populasi penduduk. Pengaruh kesadaran halal di masyarakat dirasa masih kurang optimal. Usaha kuliner terus meningkat namun kenyataannya sertifikasi halal yang menjamin halal haram suatu produk juga masih minim, ditambah lagi terus bertambahnya minat beli konsumen di Kota Semarang akan produk siap saji yang secara garis besar masih dikuasai oleh pihak asing. Penelitian ini merupakan bentuk metode kuantitatif yang menyebarkan melalui kuesioner. Populasi dalam penelitian ini adalah konsumen mahasiswa muslim yang pernah membeli dan memakan produk OriChick di Kota semarang. Sampel total berjumlah 100 responden dengan pendekatan purposive sampling. Penelitian ini menggunakan teknik analisis regresi linier berganda yang data diolah menggunakan SPSS Statistics 23. Hasil analisis menunjukkan bahwa harga dan religiusitas berpengaruh positif dan signifikan terhadap keputusan pembelian. Sedangkan untuk variabel kesadaran halal dan pelayanan tidak berpengaruh signifkan terhadap keputusan pembelian. Secara simultan hasil dari kesadaran halal, harga, pelayanan dan religiusitas berpengaruh simultan terhadap keputusan pembelian. Hasil dari uji Nilai R square sebesar 0,346 menunjukkan bahwa 34\% keputusan pembelian dapat dijelaskan oleh variabel independen dan sisanya sebesar $66 \%$ dijelaskan oleh faktor lain diluar penelitian.
\end{abstract}

Kata kunci: Kesadaran halal, harga, pelayanan, religiusitas dan keputusan pembelian. 


\section{PENDAHULUAN}

Indonesia merupakan pasar konsumen muslim yang sangat potensial. Waharini \& Purwantini (2018) menjelaskan tentang laporan State of The Global Islamic Economy yang menempatkan Indonesia diperingkat pertama untuk konsumen produk makanan halal yaitu sebesar \$154,9 Miliar. Hal tersebut sejalan dengan laporan yang disampaikan Lembaga Pengkajian Pangan, Obat-Obatan, dan Kosmetik Majelis Ulama Indonesia (LPPOM MUI) menyatakan bahwa Indonesia berpotensi sebagai Pusat Halal Dunia atau World Halal Centre yang sangat strategis bagi Indonesia di pasar Halal internasional (Khoerunnisa et al.2016).

Makanan merupakan kebutuhan dasar manusia yang paling esensial untuk mempertahankan kehidupan. UndangUndang Nomor 18 Tahun 2012 menyatakan bahwa pangan merupakan kebutuhan dasar manusia yang paling utama dan pemenuhannya merupakan bagian dari hak asasi setiap rakyat Indonesia. Perspektif agama Islam, secara umum makanan digolongkan pada halal dan haram. Saniatun dan Jono (2018) menjelaskan produk halal mengacu pada produk-produk yang memenuhi syarat syar'i yang mencegah keharaman, baik ditinjau dari segi zatnya maupun selain zatnya.
Aisyah (2012) menunjukkan sebanyak $57.9 \%$ konsumen makanan di Indonesia selalu memperhatikan label halal ketika membeli lalu sebagian dari mereka ingin pencatuman label halal ini diwajibkan $86 \%$ serta apabila mereka mendapatkan makanan yang tidak berlabel halal, kebanyakan konsumen memilih mencari alternatif lain sebagai pengganti $66.2 \%$ dan merekapun bersedia membayar lebih mahal untuk produk halal $40.6 \%$. Kurangnya kesiapan Indonesia bersaing dalam pasar produk halal disebabkan juga karena masih kurangnya kesadaran masyarakat akan pentingnya produk makanan halal. Pemahaman konsep kesadaran halal akhir ini sudah bukan terfokus pada masalah keagamaan melainkan sudah masuk pada keamanan pangan (food safety).

Dinas Koperasi UMKM Jawa Tengah hanya mampu memberikan fasilitas sertifikasi halal terhadap 500 UMKM saja, di luar itu pengusaha harus berupaya mengajukan sendiri. Namun dilapangan, Dinas Koperasi UMKM Jawa Tengah pada tahun 2018 jumlah total UMKM yang menerima fasilitas hanya sebanyak 150 unit. Salah satu bahan makanan utama yang patut diperhatikan adalah pola makan makanan dan minuman jadi yang belum jelas kandungan produksinya.

Tabel 1. Presentase Pengeluaran Perkapita Sebulan Konsumsi menurut Kelompok Komuditas 2015-2019

\begin{tabular}{|l|c|c|c|c|c|}
\hline Kelompok Komuditas & $\mathbf{2 0 1 5}$ & $\mathbf{2 0 1 6}$ & $\mathbf{2 0 1 7}$ & $\mathbf{2 0 1 8}$ & $\mathbf{2 0 1 9}$ \\
\hline Padi & 11,99 & 9,35 & 7,96 & 7,80 & 7,46 \\
\hline Umbi-umbian & 0,69 & 0,60 & 0,67 & 0,69 & 0,64 \\
\hline Ikan & 5,38 & 4,91 & 6,07 & 6,54 & 6,38 \\
\hline Daging & 6,29 & 5,49 & 6,19 & 5,35 & 4,84 \\
\hline Telur dan Susu & 9,11 & 7,65 & 7,04 & 7,03 & 6,86 \\
\hline Sayur-sayuran & 5,93 & 6,25 & 7,19 & 6,07 & 5,83 \\
\hline Kacang-kacangan & 3,11 & 2,60 & 2,32 & 1,92 & 2,03 \\
\hline
\end{tabular}




\begin{tabular}{|l|c|c|c|c|c|}
\hline Buah-buahan & 7,21 & 5,02 & 5,58 & 5,84 & 6,74 \\
\hline Minyak dan Kelapa & 2,56 & 2,24 & 2,24 & 2,03 & 1,91 \\
\hline Bahan minuman & 3,03 & 3,11 & 2,80 & 2,77 & 2,36 \\
\hline Bumnbu-bumbuan & 1,34 & 1,58 & 1,60 & 1,69 & 1,44 \\
\hline Bahan makanan lain & 2,04 & 1,91 & 1,91 & 1,96 & 1,65 \\
\hline Makan minum jadi & 33,66 & 39,21 & 40,90 & 43,60 & 45,06 \\
\hline Rokok dan Tembakau & 7,68 & 10,08 & 7,52 & 6,71 & 6,79 \\
\hline \multicolumn{1}{|c|}{ Total } & 100.0 & 100.0 & 100.0 & 100.0 & 100.0 \\
\hline
\end{tabular}

Sumber : Badan Pusat Statistik Kota Semarang 2019,diolah.

OriChick adalah perusahaan rumah makan cepat saji waralaba yang bergerak di bidang jasa yang sangat berkembang. Konsep menyajikan makanan yang sehat, berkualitas, halal, dengan cita rasa yang khas dan harga terjangkau bagi semua kalangan masyarakat yang diolah dengan bumbu pilihan, salah satu keunikan utama Ori Chick adalah dengan pengolahan ala Timur Tengah. OriChick sudah membuka cabang-cabang di kota Semarang sekitar hampir 28 gerai dan terdapat beberapa area terlaris yaitu Fatmawati, Pucang Gading, Tembalang, Klipang, Gajah dan Ngaliyan.

Aryani dan Rosinta (2010) menyatakan bahwa keputusan perusahaan melakukan tindakan perbaikan pelayanan yang sistematis merupakan payung yang menentukan dalam menindaklanjuti komplain konsumen dari suatu kegagalan sehingga pada akhirnya mampu mengikat loyalitasi konsumen. Namun pada realitanya, hingga saat ini sudah ada hampir 4 sampai 5 gerai yang gulung tikar akibat salah konsep diawal dan jika dilihat dari sektor yang sudah berkembang maju yang dinyatakan berkualitas ataupun kompeten hanya terdapat dua sektor yaitu hanya area fatmawati dan tembalang. Sebenarnya fasilitas sertifikasi halal bagi setiap bisnis dirasa penting terlebih untuk kesadaran halal di masyarakat, selain melihat pasar konsumen yang mayoritas beragama islam, hal ini juga dapat menjadi pendorong awal munculnya bisnis berbasis Syariah di Indonesia.

Tabel 2. Data Portofolio OriChick

\begin{tabular}{|l|c|c|c|c|c|}
\hline $\begin{array}{l}\text { Keteranga } \\
\mathbf{n}\end{array}$ & $\begin{array}{c}\text { November } \\
\mathbf{2 0 1 8}\end{array}$ & $\begin{array}{c}\text { Maret } \\
\mathbf{2 0 1 9}\end{array}$ & $\begin{array}{c}\text { Juli } \\
\mathbf{2 0 1 9}\end{array}$ & $\begin{array}{c}\text { November } \\
\mathbf{2 0 1 9}\end{array}$ & $\begin{array}{c}\text { Maret } \\
\mathbf{2 0 2 0}\end{array}$ \\
\hline $\begin{array}{l}\text { Cabang Ori } \\
\text { Chick }\end{array}$ & 1 & 5 & 10 & 20 & 27 \\
\hline $\begin{array}{l}\text { Karyawan } \\
\text { Ori Chick }\end{array}$ & 5 & 15 & 25 & 55 & 65 \\
\hline $\begin{array}{l}\text { Total } \\
\text { Penjualan } \\
\begin{array}{l}\text { Ori Chick } \\
\text { (rupiah) }\end{array}\end{array} 10.000 .000$ & 45.000 .000 & 85.000 .000 & 135.000 .000 & 178.000 .000 \\
\hline
\end{tabular}

Sumber : OriChick 2020, diolah.

Tabel 2 diatas menunjukkan bahwa perkembangan OriChick terjadi peningkatan yang positif setiap 5 (lima) bulan terakhir baik dilihat dari pembukaan tiap cabang, karyawan bahkan total penjualannya. Kirana (2015) menjelaskan tentang tingginya konsumen produk J.Co Donuts \& Coffe di Kota Semarang tiap tahunnya, namun yang patut ditelaah lebih lanjut adalah status produknya yang 
belum memiliki sertifikasi halal oleh MUI. Hal ini selaras dengan OriChick yang perlu dipertimbangkan karena belum adanya sertifikasi halal resmi dari MUI padahal pada Undang-Undang No.3 tahun 2014 sudah mewajibkan bahwa segala produk yang beredar dan diperjual-belikan di Indonesia wajib memiliki sertifikat halal, terkecuali produk non-halal atau haram.

\section{TINJAUAN PUSTAKA}

\section{Teori Perilaku Konsumsi}

Mangkunegara dalam Subianto (2007) mengatakan perilaku konsumen adalah tindakan-tindakan yang dilakukan oleh individu, kelompok atau organisasi yang berhubungan dengan proses pengambilan keputusan dalam mendapatkan serta menggunakan barangbarang atau jasa ekonomis yang dapat dipengaruhi lingkungan.

\section{Keputusan Pembelian}

Keputusan Pembelian yang dimaksudkan dalam penelitian ini adalah keputusan konsumen untuk membeli produk makanan dan minuman. Schiffman dan Kanuk dalam Muhammad (2012) mengatakan "the selection of an option from two or alternative choice" dapat diterangkan sebagai bentuk keputusan pembeli dimana dia memilih salah satu produk dari beberapa alternatif pilihan produk yang sudah tersedia.

\section{Kesadaran Halal}

Kesadaran mencerminkan langkah pertama dari proses pembelian, di mana konsumen yang terutama tidak berpengalaman dengan produk atau layanan menjadi akrab dengan itu. Kesadaran merupakan kemampuan untuk memahami, merasakan dan menjadi sadar akan suatu peristiwa dan objek. Kesadaran adalah konsep tentang mengisyaratkan pemahaman dan kesan tentang peristiwa atau subjek (Aziz \& Chok, 2013).

\section{Harga}

Kotler \& Keller (2009) menyatakan bahwa harga adalah jumlah uang yang dibebankan untuk suatu produk atau layanan, atau jumlah nilai yang ditukar pelanggan untuk manfaat memiliki atau menggunakan produk atau layanan. Secara garis besar, persepsi harga didefinisikan sebagai persepsi pelanggan tentang apa yang dikorbankan untuk mendapatkan produk atau layanan Zeithaml (1988).

\section{Pelayanan}

Pelayanan merupakan tolak ukur dalam menentukan minat beli atau tidaknya seorang pengguna jasa, karena melalui pelayanan akan dapat menilai kinerja dan merasakan puas atau tidaknya mereka dengan layanan yang diberikan oleh penyedia jasa. Lewis dalam Sarini (2013) menyebutkan layanan secara sederhana bisa diartikan sebagai ukuran seberapa bagus tingkat layanan yang diberikan mampu sesuai dengan ekspektasi pelanggan.

\section{Religiusitas}

Religiusitas adalah penghayatan agama seseorang yang menyangkut simbol, keyakinan, nilai dan perilaku yang didorong oleh kekuatan spiritual (Muhammad, 2012). Secara instansial, religiusitas merupakan hubungan antara ketaatan manusia dengan tuhannya yang bersifat mengikat. Ahmad dalam Nurhayati \& Hendar (2019) menambahkan agama merupakan indikator yang sangat penting dalam setiap mengambil keputusan yang mengarahkan seseorang untuk berperilaku secara legal dan etis.

\section{METODE}

Variabel dependen pada penelitian ini adalah keputusan pembelian pada mahasiswa muslim di kota Semarang, sedangkan variabel independen dalam penelitian ini adalah kesadaran halal, harga, pelayanan dan religiusitas. Populasi dalam penelitian ini adalah seluruh mahasiswa muslim pada semua universitas di kota Semarang berjumlah 125 orang. Sampel yang digunakan adalah mahasiswa 
aktif di kota Semarang, beragama Islam dan mengkonsumsi produk OriChick 1 kali dalam 1 bulan terakhir .yang berjumlah 100 orang dengan menggunakan teknik purposive sampling. Sedangkan metode pengumpulan data digunakan adalah penyebaran kuesioner dan melalui googleform lalu untuk studi literatur yang diambil dari buku, jurnal, dan internet. Jenis data pada penelitian ini berupa kuantitatif. Analisis data yang digunakan adalah uji validitas, Uji, uji reabilitas, uji normalitas, uji multikolineritas, uji heteerokedaksitas, regresi linier berganda, uji F, uji T dan uji determinasi $\left(\mathrm{R}^{2}\right)$.

\section{HASIL PEMBAHASAN \\ Gambaran Umum Responden}

Responden pada penelitian ini berjumlah 100 orang. Umur terendah pada penelitian ini yaitu 19 tahun, sedangkan umur tertinggi 26 tahun. Umur rata-rata mahasiswa di Kota Semarang berada pada interval 21-23 tahun

Tabel 3. Identitas Responden menurut Umur

\begin{tabular}{llcc}
\hline No. & Usia & Responden & Persentase(\%) \\
\hline 1. & $18-20$ Tahun & 19 & 19 \\
2. & $21-23$ Tahun & 69 & 69 \\
3. & $24-26$ Tahun & 12 & 12 \\
\hline & Jumlah & 100 & 100
\end{tabular}

Sumber : Data primer 2020, diolah

Identitas responden menurut universitas di Kota Semarang pada penelitian ini jumlah terbanyak adalah Univeristas Diponegoro yang berjumlah
78 mahasiswa, sedangkan Universitas terendah pada penelitian ini adalah UIN Walisongo dan Unisbank yang berjumlah 2 mahasiswa.

Tabel 4. Identitas Responden menurut Universitas

\begin{tabular}{llcc}
\hline No. & Universitas & Responden & Persentase(\%) \\
\hline 1. & UNDIP & 78 & 78 \\
2. & UNNES & 7 & 7 \\
3. & UDINUS & 5 & 5 \\
4. & UNISULA & 3 & 3 \\
5. & UIN Walisongo & 2 & 2 \\
6. & UNISBANK & 2 & 2 \\
7. & USM & 3 & 3 \\
\hline & Jumlah & 100 & 100
\end{tabular}

Sumber : Data primer 2020, diolah

Pada tabel 5 menjelaskan bahwa total uang saku/ pendapatan mahasiswa tertinggi pada rentang nominal < Rp. 1.500.000. 
Sedangkan uang saku/ pendapatan 3.000.001- Rp. 4.500.000. terendah pada nominal $\mathrm{Rp}$.

Tabel 5. Identitas Responden menurut Pendapatan/ Uang Saku

\begin{tabular}{llcc}
\hline No. & $\begin{array}{l}\text { Pendapatan per } \\
\text { Bulan }\end{array}$ & Responden & Persentase(\%) \\
\hline 1. & $\begin{array}{l}\text { < Rp. } \\
1.500 .000\end{array}$ & 54 & 54 \\
2. & $\begin{array}{l}\text { Rp. } 1.500 .001- \\
\text { Rp. } 3.000 .000\end{array}$ & 33 & 33 \\
3. & $\begin{array}{l}\text { Rp. } 3.000 .001- \\
\text { Rp. } 4.500 .000\end{array}$ & 4 & 4 \\
4. & $\begin{array}{l}\text { > Rp. } \\
\text { 4.500.000 }\end{array}$ & 9 & 9 \\
\hline & Jumlah & 100 & 100
\end{tabular}

Sumber : Data primer 2020, diolah

Pada tabel 6 menjelaskan bahwa rata-rata mahasiswa di Kota Semarang jika dilihat dari Pendidikan Agama pada penelitian ini lebih condong pada informal yaitu keluarga dan lingkungan sekitar.

Tabel 6. Identitas Responden menurut Pendidikan Agama

\begin{tabular}{llcc}
\hline No. & Pendidikan Agama & Responden & Persentase(\%) \\
\hline 1. & $\begin{array}{l}\text { Formal : Madrasah } \\
\text { Ibtidaiyah, } \\
\text { Tsanawiyah, MAN }\end{array}$ & 27 & 27 \\
2. & $\begin{array}{l}\text { Non Formal : } \\
\text { TPQ/TPA }\end{array}$ & 30 & 30 \\
3. & $\begin{array}{l}\text { Informal : Keluarga } \\
\text { dan lingkungan } \\
\text { sekitar }\end{array}$ & 43 & 43 \\
\hline & Jumlah & 100 & 100 \\
\hline
\end{tabular}

Sumber : Data primer 2020, diolah

\section{Uji Validitas dan Reabilitas}

Pengujian validitas

diperlukan dalam suatu penelitian, khususnya yang menggunakan kuesioner dalam mendapatkan data. Pengujian validitas dilakukan untuk mengetahui keabsahan menyangkut pemahaman mengenai 
Tabel 7. Hasil Uji Validitas

\begin{tabular}{|c|c|c|c|}
\hline Variabel & Indikator & $\begin{array}{l}\text { R } \\
\text { hitung }\end{array}$ & R Tabel \\
\hline \multirow[t]{5}{*}{ Kesadaran Halal (X1) } & $\begin{array}{l}\text { (indikator arti } \\
\text { halal) }\end{array}$ & 0.792 & 0.1966 \\
\hline & $\begin{array}{l}\text { (indicator } \\
\text { produk halal) }\end{array}$ & 0.836 & 0.1966 \\
\hline & $\begin{array}{l}\text { (indicator logo } \\
\text { halal) }\end{array}$ & 0.836 & 0.1966 \\
\hline & $\begin{array}{l}\text { (indicator } \\
\text { produk syubhat } \\
\text { / meragukan) }\end{array}$ & 0.648 & 0.1966 \\
\hline & $\begin{array}{l}\text { (indicator } \\
\text { produk syubhat } \\
\text { / meragukan) }\end{array}$ & 0.724 & 0.1966 \\
\hline \multirow[t]{5}{*}{ Harga (X2) } & $\begin{array}{l}\text { (indicator } \\
\text { harga } \\
\text { terjangkau) }\end{array}$ & 0.795 & 0.1966 \\
\hline & $\begin{array}{l}\text { (indicator } \\
\text { harga bersaing) }\end{array}$ & 0.758 & 0.1966 \\
\hline & $\begin{array}{l}\text { (indicator } \\
\text { harga sesuai) }\end{array}$ & 0.858 & 0.1966 \\
\hline & $\begin{array}{l}\text { (indicator } \\
\text { harga sesuai } \\
\text { dengan } \\
\text { manfaat } \\
\text { produk) }\end{array}$ & 0.805 & 0.1966 \\
\hline & $\begin{array}{l}\text { (indicator } \\
\text { harga } \\
\text { informatif) }\end{array}$ & 0.704 & 0.1966 \\
\hline \multirow[t]{5}{*}{ Pelayanan (X3) } & $\begin{array}{l}\text { (indicator } \\
\text { berwujud/ } \\
\text { tangibles) }\end{array}$ & 0.632 & 0.1966 \\
\hline & $\begin{array}{l}\text { (indicator } \\
\text { berwujud/ } \\
\text { tangibles) }\end{array}$ & 0.651 & 0.1966 \\
\hline & $\begin{array}{l}\text { (indicator } \\
\text { berwujud/ } \\
\text { tangibles) }\end{array}$ & 0.670 & 0.1966 \\
\hline & $\begin{array}{l}\text { (indicator } \\
\text { keandalan/ } \\
\text { reliability) }\end{array}$ & 0.767 & 0.1966 \\
\hline & (indicator & 0.721 & 0.1966 \\
\hline
\end{tabular}




\begin{tabular}{|c|c|c|c|}
\hline Variabel & Indikator & $\begin{array}{l}\mathbf{R} \\
\text { hitung }\end{array}$ & R Tabel \\
\hline & $\begin{array}{l}\text { keandalan/ } \\
\text { reliability) }\end{array}$ & & \\
\hline & $\begin{array}{l}\text { (indicator } \\
\text { keandalan/ } \\
\text { reliability) }\end{array}$ & 0.567 & 0.1966 \\
\hline & $\begin{array}{l}\text { (indicator } \\
\text { ketanggapan/ } \\
\text { responsiveness) }\end{array}$ & 0.639 & 0.1966 \\
\hline & $\begin{array}{l}\text { (indicator } \\
\text { ketanggapan/ } \\
\text { responsiveness) }\end{array}$ & 0.542 & 0.1966 \\
\hline & $\begin{array}{l}\text { (indicator } \\
\text { ketanggapan/ } \\
\text { responsiveness) }\end{array}$ & 0.575 & 0.1966 \\
\hline & $\begin{array}{l}\text { (indicator } \\
\text { jaminan } \\
\text { kepastian/ } \\
\text { assurance) }\end{array}$ & 0.745 & 0.1966 \\
\hline & $\begin{array}{l}\text { (indicator } \\
\text { jaminan } \\
\text { kepastian/ } \\
\text { assurance). }\end{array}$ & 0.632 & 0.1966 \\
\hline & $\begin{array}{l}\text { (indicator } \\
\text { jaminan } \\
\text { kepastian/ } \\
\text { assurance). }\end{array}$ & 0.574 & 0.1966 \\
\hline & $\begin{array}{l}\text { (indicator } \\
\text { empati/ } \\
\text { empathy) }\end{array}$ & 0.527 & 0.1966 \\
\hline & $\begin{array}{l}\text { (indicator } \\
\text { empati/ } \\
\text { empathy) }\end{array}$ & 0.668 & 0.1966 \\
\hline & $\begin{array}{l}\text { (indicator } \\
\text { empati/ } \\
\text { empathy) }\end{array}$ & 0.574 & 0.1966 \\
\hline Religiusitas (X4) & $\begin{array}{l}\text { (indicator } \\
\text { keyakinan } \\
\text { agama) } \\
\end{array}$ & 0.813 & 0.1966 \\
\hline & $\begin{array}{l}\text { (indicator } \\
\text { keyakinan } \\
\text { agama) }\end{array}$ & 0.799 & 0.1966 \\
\hline & $\begin{array}{l}\text { (indicator } \\
\text { keyakinan } \\
\text { agama) }\end{array}$ & 0.805 & 0.1966 \\
\hline
\end{tabular}




\begin{tabular}{|c|c|c|c|}
\hline Variabel & Indikator & $\begin{array}{l}\text { R } \\
\text { hitung }\end{array}$ & R Tabel \\
\hline & $\begin{array}{l}\text { (indicator } \\
\text { praktik agama) }\end{array}$ & 0.735 & 0.1966 \\
\hline & $\begin{array}{l}\text { (indicator } \\
\text { praktik agama) }\end{array}$ & 0.701 & 0.1966 \\
\hline & $\begin{array}{l}\text { (indicator } \\
\text { praktik agama) }\end{array}$ & 0.526 & 0.1966 \\
\hline & $\begin{array}{l}\text { (indicator } \\
\text { praktik agama) }\end{array}$ & 0.497 & 0.1966 \\
\hline & $\begin{array}{l}\text { (indicator } \\
\text { praktik agama) }\end{array}$ & 0.734 & 0.1966 \\
\hline & $\begin{array}{l}\text { (indicator } \\
\text { praktik agama) }\end{array}$ & 0.752 & 0.1966 \\
\hline & $\begin{array}{l}\text { (indicator } \\
\text { altruisme } \\
\text { agama) }\end{array}$ & 0.620 & 0.1966 \\
\hline & $\begin{array}{l}\text { (indicator } \\
\text { altruisme } \\
\text { agama) } \\
\end{array}$ & 0.693 & 0.1966 \\
\hline & $\begin{array}{l}\text { (indicator } \\
\text { altruisme } \\
\text { agama) } \\
\end{array}$ & 0.707 & 0.1966 \\
\hline & $\begin{array}{l}\text { (indicator } \\
\text { pengalaman } \\
\text { agama) }\end{array}$ & 0.755 & 0.1966 \\
\hline & $\begin{array}{l}\text { (indicator } \\
\text { pengalaman } \\
\text { agama) }\end{array}$ & 0.605 & 0.1966 \\
\hline & $\begin{array}{l}\text { (indicator } \\
\text { pengalaman } \\
\text { agama) }\end{array}$ & 0.723 & 0.1966 \\
\hline \multirow[t]{5}{*}{ Keputusan Pembelian (Y) } & $\begin{array}{l}\text { (indicator } \\
\text { makanan } \\
\text { beragam) }\end{array}$ & 0.717 & 0.1966 \\
\hline & $\begin{array}{l}\text { (indicator } \\
\text { evaluasi } \\
\text { alternatif lain) }\end{array}$ & 0.682 & 0.1966 \\
\hline & $\begin{array}{l}\text { (indicator } \\
\text { membeli } \\
\text { produk halal) }\end{array}$ & 0.728 & 0.1966 \\
\hline & $\begin{array}{l}\text { (indicator } \\
\text { memastikan } \\
\text { produk halal) }\end{array}$ & 0.746 & 0.1966 \\
\hline & $\begin{array}{l}\text { (indicator } \\
\text { mengkonsumsi }\end{array}$ & 0.699 & 0.1966 \\
\hline
\end{tabular}




\begin{tabular}{|l|l|l|l|}
\hline Variabel & Indikator & $\begin{array}{l}\text { R } \\
\text { hitung }\end{array}$ & R Tabel \\
\hline & makanan halal) & & \\
\hline
\end{tabular}

Sumber : Data primer 2020, diolah

Berdasarkan tabel diatas bahwa seluruh perhitungan $r$ hitung lebih besar dari $r$ tabel yaitu 0.1966, maka data dikatakan bahwa seluruh indicator yang digunakan dalam penelitian ini dikatakan valid.

cara membandingkan angka cronbach alpha dengan ketentuan nilai cronbach alpha minimal adalah 0,6. Artinya jika nilai cronbach alpha yang didapatkan dari hasil perhitungan SPSS lebih besar dari 0,6 maka disimpulkan kuesioner tersebut reliabel, sebaliknya jika cronbach alpha lebih kecil dari 0,6 maka disimpulkan tidak reliabel.

Tabel 8. Kesadaran branch

\begin{tabular}{|l|l|l|l|}
\hline Variabel & $\begin{array}{l}\text { Croncbach } \\
\text { Alpha }\end{array}$ & $\begin{array}{l}\text { Standard } \\
\text { Alpha }\end{array}$ & Keterangan \\
\hline $\begin{array}{l}\text { Kesadaran } \\
\text { Halal }\end{array}$ & 0.825 & 0.6 & Reliabel \\
\hline Harga & 0.840 & 0.6 & Reliabel \\
\hline Pelayanan & 0.891 & 0.6 & Reliabel \\
\hline Religiusitas & 0.910 & 0.6 & Reliabel \\
\hline $\begin{array}{l}\text { Keputusan } \\
\text { Pembelian }\end{array}$ & 0.751 & 0.6 & Reliabel \\
\hline
\end{tabular}

Sumber : Data primer 2020, diolah

Berdasarkan tabel diatas

menunjukkan bahwa seluruh variabel penelitian ini memiliki Croncbach Alpha yang lebih besar dari Standard Alpha sebesar 0,6. Berdasarkan hasil tersebut maka dikatakan bahwa seluruh variabel penelitian dinyatakan reliabel.

\section{Uji Asumsi Klasik}

Uji asumsi klasik dilakukan untuk mendeteksi ada atau tidaknya penyimpangan terhadap ketidaknormalan data yang digunakan pada suatu penelitian. Pengujian pertama yang dilakukan adalah uji normalitas. Pengujian normalitas pada penelitian ini dilakukan dengan uji statistik nonparametrik Kolmogorov-Smirnov (K-S). Suatu data dinyatakan "normal" jika nilai signifikan lebih besar dari 0,05 pada taraf signifikansi alpha 5\%. Sebaliknya, apabila nilai signifikasi lebih kecil dari 0,05 pada taraf signifikasi alpha 5\% maka data dikatakan tidak normal. 
Tabel 9

\begin{tabular}{|l|r|}
\hline & \multicolumn{2}{|c|}{$\begin{array}{c}\text { Unstandarized } \\
\text { Residual }\end{array}$} \\
\hline $\mathrm{N}$ & 100 \\
\hline Test Statistic & .062 \\
\hline $\begin{array}{l}\text { Asymp.sig. } \quad(2- \\
\text { tailed) }\end{array}$ & $.200^{\mathrm{c}, \mathrm{d}}$ \\
\hline
\end{tabular}

Sumber : Data primer 2020, diolah

Berdasarkan pada tabel diatas, menunjukkan bahwa nilai dari uji Kolmogorov-Smirnov > 0,5 yaitu sebesar 0,2. Hal ini menunjukkan bahwa seluruh variabel dalam penelitian ini terdisribusi secara normal.

Uji Multikolonieritas digunakan untuk menguji apakah dalam sebuah model regresi ditemukan adanya korelasi antar variabel independen. Hasil uji multikolonieritas dapat dilihat dari besarnya tolerance value dan variance inflation factor (VIF). Model regresi dapat dikatakan baik jika tidak terdapat multikolonieritas. Apabila nilai tolerance $>0,1$ dan nilai VIF $<10$ maka tidak terdapat multikolonieritas. Berikut hasil dari uji multikolonieritas.

Tabel 10

\begin{tabular}{|l|l|l|}
\hline Variabel & Tolerance & VIF \\
\hline Kesadaran Halal &, 581 & 1,720 \\
\hline Harga &, 590 & 1,694 \\
\hline Pelayanan &, 462 & 2,165 \\
\hline Religiusitas &, 649 & 1,542 \\
\hline
\end{tabular}

Sumber : Data primer 2020, diolah

Pada tabel 10 diatas menunjukkan bahwa deteksi multikolinearitas menunjukkan variabel-variabel independen yang digunakan dalam penelitian ini tidak saling berkorelasi. Maka dapat ditarik kesimpulan bahwa tidak terdapat gejala multikolinearitas dalam model regresi.

Uji heteroskedastisitas bertujuan untuk menguji apakah dalam model reresi terjadi ketidaksamaan variance dari residual satu pengamatan ke pengamatan yang lain. Jika variance dari residual suatu pengamatan ke pengamatan lain tetap, maka disebut homoskedastisitas dan jika berbeda disebut heterokedastisitas (Ghozali, 2013). 


\section{Gambar 1}

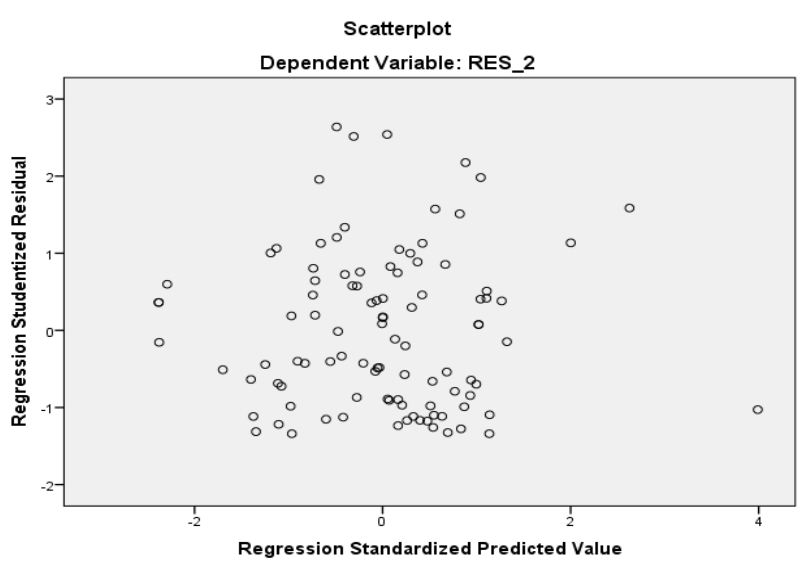

Sumber : Data primer 2020, diolah

Berdasarkan Gambar diatas menunjukkan bahwa titik-titik telah menyebar secara acak diatas dan dibawah angka 0 dan sumbu Y, dengan demikian dapat disimpulkan bahwa pada model regresi tidak terdapat gejala heteroskedastisitas.

\section{Analisis Hipotesis}

Analisis Regresi Linier Berganda digunakan untuk menganalisis pengaruh variabel independen terhadap variabel dependen. Analisis regresi berganda ini mengukur seberapa besar pengaruh variabel independen yaitu: kesadaran halal (X1), harga (X2), pelayanan (X3) dan religiusitas (X4) terhadap variabel dependen yaitu keputusan pembelian

(Y).

Tabel 11

\begin{tabular}{|c|c|c|c|}
\hline \multirow[t]{2}{*}{ Variabel } & \multicolumn{2}{|c|}{ Unstandardized Coefficients } & \multirow{2}{*}{$\begin{array}{c}\text { Standardized } \\
\text { Coefficients } \\
\text { Beta } \\
\end{array}$} \\
\hline & $\mathbf{B}$ & Std. Error & \\
\hline (Constant) & 6,718 & 2,234 & \\
\hline Kesadaran halal &,- 046 & 100 &,- 050 \\
\hline Harga & ,282 & ,092 & ,331 \\
\hline Pelayanan & ,030 & ,044 & ,084 \\
\hline Religiusitas & 114 & 034 & ,346 \\
\hline
\end{tabular}

Sumber : Data primer 2020, diolah

$$
\begin{aligned}
& Y 1=(-0,050) X 1+0,331 X 2+0,084 X 3+0,346 X 4+e \\
& Y=\text { Keputusan pembelian }
\end{aligned}
$$




$$
\begin{aligned}
& \text { X1 = Kesadaran halal } \\
& \text { X2 = Harga } \\
& \text { X3 = Pelayanan } \\
& \text { X4 = Religiusitas } \\
& e=\text { Error }
\end{aligned}
$$

1. Koefisien regresi pada variabel kesadaran halal (X1) berpengaruh negatif terhadap keputusan pembelian (Y) sebesar -0,050 yang artinya jika faktor Kesadaran halal terjadi peningkatan, maka tingkat keputusan pembelian produk OriChick tidak mengalami peningkatan, dengan asumsi variabel lain tetap (tidak berubah).

2. Koefisien regresi pada variabel harga (X2) berpengaruh positif terhadap keputusan pembelian (Y) sebesar 0,331 yang artinya jika faktor harga terjadi peningkatan, maka tingkat keputusan pembelian produk OriChick akan meningkat, dengan asumsi variabel lain tetap (tidak berubah).

3. Koefisien regresi pada variabel pelayanan (X3) berpengaruh positif terhadap keputusan pembelian (Y) sebesar 0,084 yang artinya jika faktor pelayanan terjadi peningkatan, maka tingkat keputusan pembelian produk OriChick akan meningkat, dengan asumsi variabel lain tetap (tidak berubah).

4. Koefisien regresi pada variabel religiusitas (X4) berpengaruh positif terhadap keputusan pembelian (Y) sebesar 0,346 yang artinya jika faktor religiusitas terjadi peningkatan, maka tingkat keputusan pembelian produk OriChick akan meningkat dengan asumsi variabel lain tetap (tidak berubah).

Uji signifikasi pengaruh parsial (Uji T) memiliki tujuan untuk mengetahui seberapa jauh pengaruh variabel independent terhadap variabel dependen secara parsial.

Tabel 12

\begin{tabular}{|l|l|l|}
\hline Variabel & T & Sig \\
\hline (Constant) & 3,007 &, 003 \\
\hline Kesadaran halal &,- 461 &, 646 \\
\hline Harga & 3,070 &, 003 \\
\hline Pelayanan &, 688 &, 493 \\
\hline Religiusitas & 3,358 &, 001 \\
\hline
\end{tabular}

Sumber : Data primer 2020, diolah

Uji pengaruh simultan (Uji

F) digunakan untuk menguji pengaruh variabel independent yaitu kesadaran halal, harga, 
pelayanan dan religiusitas secara bersama atau simultan terhadap variabel dependen yaitu keputusan pembelian.

Tabel 13

\begin{tabular}{|l|l|l|l|}
\hline Model & Df & F & Sig \\
\hline Regression & 4 & 12,590 & $.000^{\mathrm{b}}$ \\
\hline Residual & 95 & & \\
\hline Total & 99 & & \\
\hline
\end{tabular}

Sumber : Data primer 2020, diolah

Berdasarkan hasil pengujian uji $\mathrm{F}$ pada tabel 4.25 menyatakan bahwa nilai $\mathrm{F}$ sebesar 12.590 lebih besar dari $\mathrm{F}$ tabel adalah $2,70(12,590>2,70)$. Dengan tingkat signifikansi 0,000 kurang dari $0,05 \quad(0,000<$ 0,05).Sehingga dapat disimpulkan bahwa variabel independent yaitu kesadaran halal, harga, pelayanan dan religiusitas berpengaruh positif dan signifikan secara simultan terhadap keputusan pembelian.
Uji koefisien Determinasi digunakan untuk mengukur seberapa jauh kemampuan model dalam menerangkan variasi variabel dependen. Nilai yang mendekati satu berarti variabelvariabel bebas memberikan hampir semua informasi yang dibutuhkan untuk memprediksi variabel terikat (Ghozali, 2013).

Tabel 14

\begin{tabular}{|l|l|l|l|}
\hline $\boldsymbol{R}$ & $\boldsymbol{R}$ Square & $\begin{array}{l}\text { Adjusted } \boldsymbol{R} \\
\text { Square }\end{array}$ & $\begin{array}{l}\text { Std. Eror of } \\
\text { the estimate }\end{array}$ \\
\hline $.589^{\mathrm{a}}$ &, 346 &, 319 & 1,85198 \\
\hline
\end{tabular}

Sumber : Data primer 2020, diolah

Hasil uji koefisien determinasi menghasilkan nilai $\mathrm{R}^{2}$ sebesar 0,346. Hal ini menunjukkan bahwa $34,6 \%$ keputusan pembelian dipengaruhi oleh variabel kesadaran halal (X1), harga (X2), pelayanan (X3) dan religiusitas (X4), serta $65,4 \%$ sisanya dipengaruhi oleh variabel lain yang tidak terdapat pada penelitian ini.

\begin{abstract}
KESIMPULAN
Hasil analisis dan pembahasan pada penelitian ini bertujuan untuk meneliti dan membahas mengenai seberapa besar pengaruh kesadaran halal, harga, pelayanan dan religiusitas terhadap keputusan pembelian produk OriChick yang dikhususkan pada mahasiswa muslim di Kota Semarang. Maka dapat disimpulkan sebagai berikut :
\end{abstract}


1. Variabel Harga dan religiusitas memiliki pengaruh positif dan signifikan terhadap keputusan pembelian produk OriChick di Kota Semarang. Hal ini mengartikan bahwa variabel harga (X2) dan religiusitas (X4) pada penelitian ini menjadi factor yang meningkatkan keputusan pembelian mahasiswa muslim pada produk OriChick di kota Semarang.

2. Variabel kesadaran halal (X1) dan pelayanan (X3) dalam peneletian ini menghasilkan sebuah kesimpulan bahwa tidak memiliki pengaruh yang signifikan terhadap keputusan pembelian mahasiswa muslim pada produk OriChick di Kota Semarang.

3. Tingkat keputusan pembelian dapat dijelaskan oleh variabel kesadaran halal (X1), harga(X2), pelayanan (X3) dan religiusitas (X4) sebesar $34,6 \%$. Sedangkan sisanya yaitu sebesar $65,4 \%$ dipengaruhi oleh variabel lain diluar variabel pada penelitian ini.

\section{DAFTAR PUSTAKA}

Aisyah, M. (2012). Pengaruh Labelisasi Halal Terhadap Keputusan Pembelian Produk Mi Instan. Jakarta: The Faculty of Economics and Business UIN Syarif Hidayatullah Jakarta, 171, 1-21.

Aryani, D., \& Rosinta, F. (2010). Pengaruh Kualitas Layanan terhadap Kepuasan Pelanggan dalam Membentuk Loyalitas Pelanggan. Jurnal Ilmu Administrasi Dan Organisasi, 17(2), 114-126.

Aziz, Y. A., \& Chok, N. V. (2013). The Role of Halal Awareness, Halal Certification, and Marketing Components in Determining Halal Purchase Intention Among Non-Muslims in Malaysia: A Structural Equation Modeling Approach. Journal of International Food and Agribusiness Marketing, 25(1), 1-23. https://doi.org/10.1080/08974438.2013.7 23997
Badan Pusat Statistik Kota Semarang. (2019). Statistik Kesejahteraan Rakyat Kota Semarang Tahun 2019. Badan Pusat Statistik Kota Semarang.

Ghozali, I. (2013). Aplikasi Analisis Multivariate Dengan Program IBM SPSS

21. Badan Penerbit Universitas Diponegoro.

Khoerunnisa, T., Sunaryo, \& Puspaningrum, A. (2016). Pengaruh Kepercayaan Agama, Logo Halal, Pemaparan, dan Alasan Kesehatan terhadap Kesadaran Merek dan Keputusan Pembelian Makanan Halal pada Penduduk Kota Malang. Ekonomi Bisnis, 21(1), 36-45.

Kirana, D. windikusuma. (2015). Sikap Masyarakat Muslim Terhadap Produk Makanan Non-Halal Di Kota Semarang. Diponegoro Journal of Management, 4 , $1-12$.

Kotler, P., \& Keller, K. L. (2009). Manajemen Pemasaran. Erlangga.

Muhammad, N. (2012). Pengaruh Tingkat Religiusitas dan Brand Liking Terhadap Pengambilan Keputusan Pembelian Produk Makanan Halal Sertifikat MUI Dengan Sikap Terhadap Merek Sebagai Variabel Intervening (Studi Pada Konsumen Kebab Turki Baba Rafi di Malang). Jurnal Ilmiah Mahasiswa FEB Universitas Brawijaya, 02(3), 16891699. https://doi.org/10.1017/CBO9781107415 324.004

Nurhasanah Saniatun, Munandar M Jono, S. M. (2018). Faktor-Faktor yang Mempengaruhi Minat Beli Produk Makanan Olahan Halal pada Konsumen. Jurnal Manajemen Dan Organisasi.

Nurhayati, T., \& Hendar, H. (2019). Personal intrinsic religiosity and product knowledge on halal product purchase intention: Role of halal product awareness. Journal of Islamic Marketing. https://doi.org/10.1108/JIMA-11-20180220

Sarini, K. (2013). Harga, Kualitas Produk Dan Kualitas Pelayanan Pengaruhnya Terhadap Keputusan Pembelian Mobil Toyota Avanza. Jurnal EMBA: Jurnal Riset Ekonomi, Manajemen, Bisnis Dan Akuntansi, 1, 1251-1259. https://doi.org/10.1002/pola.21914 
Ad-Deenar: Jurnal Ekonomi dan Bisnis Islam, VOL: 5/NO: 02 DOI : 10.30868/ad.v5i02.1316

Subianto, T. (2007). Studi Tentang Perilaku Konsumen Beserta Implikasinya Terhadap Keputusan Pembelian. Jurnal Ekonomi Modernisasi, 165-182.

Waharini, F. M., \& Purwantini, A. H. (2018). Model Pengembangan Industri Halal Food di Indonesia. Muqtasid: Jurnal
P-ISSN: 2356-1866

E-ISSN: 2614-8838

Ekonomi Dan Perbankan Syariah, 9(1), 1. https://doi.org/10.18326/muqtasid.v9i1.113

Zeithaml, V. A. (1988). Consumer Perceptions of Price, Quality, and Value: A MeansEnd. 52(July), 2-22. 